\title{
Development of a loop-mediated isothermal amplification (LAMP) assay for the identification of the invasive wood borer Aromia bungii (Coleoptera: Cerambycidae) from frass
}

\author{
Domenico Rizzo ${ }^{1}$. Nicola Luchi ${ }^{2}$ - Daniele Da Lio ${ }^{3}$. Linda Bartolini ${ }^{1}$ - Francesco Nugnes ${ }^{4}$. Giovanni Cappellini ${ }^{1}$. \\ Tommaso Bruscoli ${ }^{1}$. Chiara Salemi ${ }^{3} \cdot$ Raffaele V. Griffo $^{5}$. Antonio P. Garonna ${ }^{6}$. Elisabetta Rossi ${ }^{3}$ (B)
}

Received: 10 October 2020 / Accepted: 17 December 2020 / Published online: 19 January 2021

(c) The Author(s) 2021

\begin{abstract}
The red-necked longhorn beetle Aromia bungii (Faldermann, 1835) (Coleoptera: Cerambycidae) is native to east Asia, where it is a major pest of cultivated and ornamental species of the genus Prunus. Morphological or molecular discrimination of adults or larval specimens is required to identify this invasive wood borer. However, recovering larval stages of the pest from trunks and branches causes extensive damage to plants and is timewasting. An alternative approach consists in applying noninvasive molecular diagnostic tools to biological traces (i.e., fecal pellets, frass). In this way, infestations in host plants can be detected without destructive methods. This paper presents a protocol based on both real-time and visual loop-mediated isothermal amplification (LAMP), using DNA of A. bungii extracted from fecal particles in larval frass. Laboratory validations demonstrated the robustness of the protocols adopted and their reliability was confirmed performing an inter-lab blind panel. The LAMP assay and the qPCR SYBR Green method using the F3/B3 LAMP external primers were equally sensitive, and both were more sensitive than the conventional PCR (sensitivity $>10^{3}$ to the same starting matrix). The visual LAMP protocol, due to the relatively easy performance of the method, could be a useful tool to apply in rapid monitoring of $A$. bungii and in the management of its outbreaks.
\end{abstract}

Keywords Red-necked longhorn beetle $\cdot$ Invasive pest $\cdot$ Rapid diagnostic tool $\cdot$ Phytosanitary survey

\section{Introduction}

Accession numbers: Not applicable.

Elisabetta Rossi

elisabetta.rossi@unipi.it

1 Laboratory of Phytopathological Diagnostics and Molecular Biology, Plant Protection Service of Tuscany, Via Ciliegiole 99, 51100 Pistoia, Italy

2 Institute for Sustainable Plant Protection, National Research Council (IPSP-CNR), Via Madonna del Piano 10, Sesto Fiorentino, 50019 Florence, Italy

3 Department of Agriculture, Food and Environment, University of Pisa, Via del Borghetto 80, 56124 Pisa, Italy

4 Institute for Sustainable Plant Protection, National Research Council (IPSP-CNR), P.le Enrico Fermi 1, 80055 Portici, Italy

5 Plant Protection Service of Campania, Centro Direzionale, Isola A6, 80124 Naples, Italy

6 Department of Agricultural Sciences, University of Naples Federico II, Via Università 100, 80055 Portici, Italy
Aromia bungii (Faldermann, 1835) (Coleoptera: Cerambycidae), the red-necked longhorn beetle, is an important pest of fruit and ornamental plants of the genus Prunus, both in native areas of east Asia and in newly invaded areas of Europe and Japan (EFSA 2019; EPPO 2020; CABI 2020). $A$. bungii can infest healthy or weakened host species and complete several overlapping generations in the same tree (Ma et al. 2007). The larvae bore galleries in the trunk and main branches, causing structural weakness, dieback, and finally tree death. Biological parameters of A. bungii evaluated in the Italian population showed remarkable fertility and longevity (Russo et al. 2020).

A. bungii is in the list of priority pests in the European Union (EU 2019) and quarantine measures have been applied in Germany and Italy to eradicate this invasive pest (Hörren 2016) or to contain the risk of further outbreaks (Carella 2019). These quarantine measures can have a strong impact on nurseries and farmers. 
Early detection supported by rapid diagnostic protocols can help to identify the presence of $A$. bungii on plants irrespectively of the developmental stage of the pest, so that the efficacy of the phytosanitary monitoring in the field and at points of entry is enhanced. In the latter case, possible import delays can be avoided (Blaser et al. 2018; Poland and Rassati 2019).

The high specificity and sensitivity of DNA-based technologies allows the detection of harmful organisms even at low concentrations of DNA extracted from plant tissues (Aglietti et al. 2019; Rizzo et al. 2020a). Among the most versatile, sensitive and specific methods, loop-mediated isothermal amplification (LAMP) can be used as a fieldfriendly and cost-effective diagnostic tool (Notomi et al. 2000, 2015). Several LAMP tests have been used both in the field and in laboratories, in particular for human and animal diseases (Lucchi et al. 2010), in food safety controls (Abdulmawjood et al. 2014), as well as in identifying plant pathogens (Aglietti et al. 2019; Luchi et al. 2020; Blaser et al. 2018) and invasive insect pests (Huang et al. 2009; Hsieh et al. 2012; Fekrat et al. 2015; Przybylska et al. 2015; Ide et al. 2016a, b; Blaser et al. 2018; Sabahi et al. 2018; Rizzo et al. 2020b). LAMP is a highly specific and robust identification method for species with previously known DNA or RNA sequences and suitable for on-site application because it can be performed in a laboratory-free environment after minimal training (Kogovšek et al. 2015).

This paper presents a reliable and sensitive diagnostic test for the rapid diagnosis of A. bungii frass using the LAMP technique. The quality of this method is compared to the conventional PCR end point method and a qPCR protocol recently developed for the identification of $A$. bungii from frass (Rizzo et al. 2020a).

\section{Materials and methods}

\section{Biological samples}

The target samples included adults, larvae, and frass of $A$. bungii. Adults and larval specimens were supplied by the Department of Agricultural Sciences of the University of Naples "Federico II" and the Plant Health Service of the Campania region. In some farms situated in the pest outbreak area around Naples (Campania, Italy), where A. bungii is considered as established (Carella 2019), frass samples (Fig. 1) were collected at the trunk base of Prunus plants and individually labeled as in Rizzo et al. (2020a).

The non-target samples consisted of a set of DNA samples from the entomological biomolecular collection of the phytopathological laboratory of the Phytosanitary Service of the Tuscany Region. The non-target DNA samples were listed in a previous paper (Rizzo et al. 2020a) and included

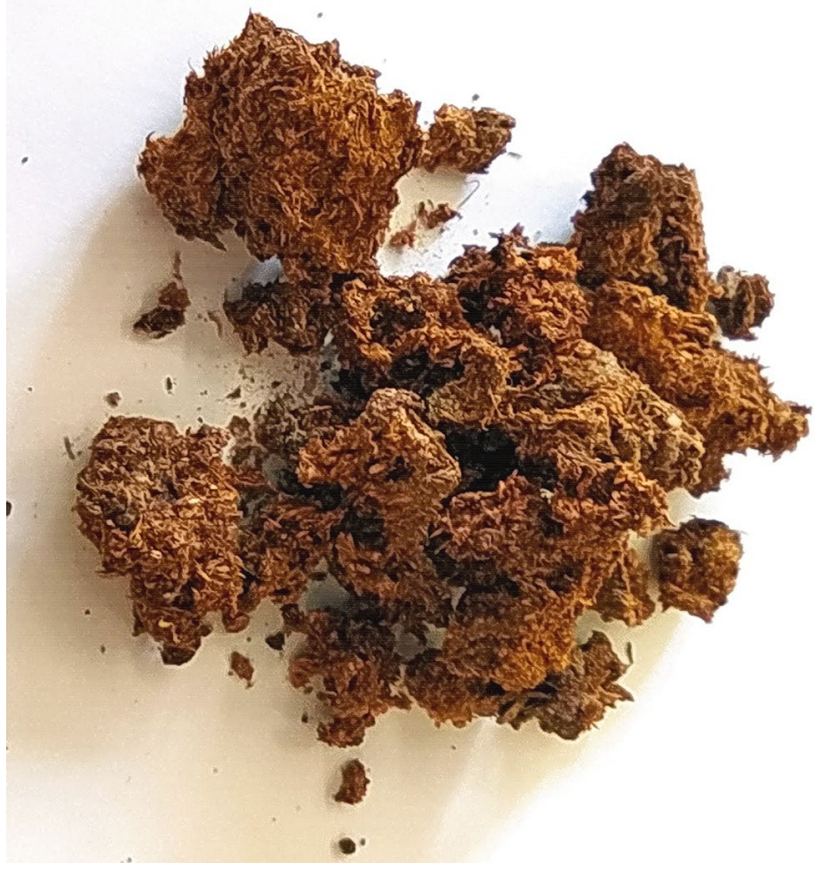

Fig. 1 Sample of Aromia bungii frass collected in the field

a total of 62 samples belonging to 26 species. They were used for testing the diagnostic specificity of the protocols. The non-target samples included, depending on the species, adults and/or larval specimens and frass samples in the case of some xylophagous species. Among the non-target species, a subset of six xylophagous species producing frass (Anoplophora chinensis (Forster), An. glabripennis (Motschulsky), Cerambyx cerdo Linnaeus, Cossus cossus Linnaeus, Sesia sp. Fabricius, and Zeuzera pyrina Linnaeus) was chosen and DNA was extracted de novo from their frass for this study. These DNA samples will be hereafter be referred to as nontarget frass samples.

\section{DNA extraction}

The DNA extraction procedure was the same for real-time and visual LAMP protocols but had some changes in relation to the matrix (frass or larvae/adults). The extraction was carried out on A. bungii frass and larvae or adults following the CTAB extraction method suggested in Li et al. (2008) with slight modifications. Specifically, in the extraction from insect frass, about $1 \mathrm{~g}$ of matrix was homogenized in a 10-mL stainless steel grinding jar along with a TissueLyzer (Qiagen, Hilden, Germany) for $10 \mathrm{~s}$ at $2000 \mathrm{opm}$. Each larva/adult was ground and homogenized individually using nylon mesh U-shaped bags (Bioreba, Reinach, Switzerland). Variable volumes ( $10 \mathrm{~mL}$ for insect frass and $1 \mathrm{~mL}$ for larvae) of $2 \%$ CTAB buffer (2\% CTAB, $1 \%$ PVP40, 100 mM Tris-HCl, pH 8.0, 1.4 M NaCl, 20 mM EDTA, 
and $1 \%$ sodium metabisulfite) were added immediately after grinding.

A volume of $0.5-1 \mathrm{~mL}$ of lysate was then incubated at $65^{\circ} \mathrm{C}$ for $10 \mathrm{~min}, 1$ volume of chloroform was added, stirred by inversion and TissueLyzer centrifuged at 13,000 rpm for $10 \mathrm{~min}$. An aliquot of $600 \mu \mathrm{L}$ was then taken from the supernatant and an equal volume of isopropanol was inserted, mixed by inversion and centrifuged at 13,000 rpm for $5 \mathrm{~min}$. The resulting pellet was dried by speed vacuum (Eppendorf, Milan, Italy) for $5 \mathrm{~min}$, then resuspended in $100 \mu \mathrm{L}$ of sterile, ultra-pure water and incubated at $65^{\circ} \mathrm{C}$ for $5 \mathrm{~min}$ and used for LAMP/qPCR/conventional PCR reactions immediately or stored at $-20^{\circ} \mathrm{C}$ until use.

This extraction protocol was used on A. bungii samples (larvae and frass) and non-target frass samples in triplicate. The amount of DNA $(\mathrm{ng} / \mu \mathrm{L})$ and the $A_{260 / 280}$ ratios were evaluated for each sample using the QIAxpert spectrophotometer (Qiagen, Hilden, Germany). To detect biological traces of insects (feces, etc.) in the frass samples, the quality of the extracted DNA was estimated using a dual-labeled qPCR targeting a highly conserved region of the $18 \mathrm{~S}$ rDNA (Ioos et al. 2009).

LAMP reaction targeting the cytochrome c oxidase subunit I (COI) gene was also performed on frass samples to assess the amplifiability of the extracted DNA from wood (Tomlinson et al. 2010b).

\section{Design of $A$. bungii LAMP and conventional PCR end point primers}

In the LAMP reaction, six primers (F3/B3, FIP/BIP and LoopF/LoopB) were designed to specifically target a fragment of the cytochrome oxidase subunit I (COI) gene of $A$. bungii (accession $\mathrm{n}$. KF737790). The primers were designed using the LAMP Designer software (OptiGene Limited, Horsham, UK) and synthesized by Eurofins Genomics (Ebersberg, Germany). The sequences of the primers are shown in Table 1.
ncbi.nlm.nih.gov/BLAST; Altschul et al. 1990). A. bungii LAMP homologous sequences were downloaded from GenBank and used for alignments to test the in silico specificity of the designed primers. The alignments were performed using the MAFFT software implemented in Geneious 10.2.6 (Kearse et al. 2012), set with the default parameters (Fig. 2).

To evaluate and compare the analytical sensitivity, specificity and reliability of the developed real-time and visual LAMP protocols, conventional PCR (end point) assays for the diagnosis of $A$. bungii were designed (Table 2) using the OligoArchitect ${ }^{\mathrm{TM}}$ Primers and Probe Online software (Sigma-Aldrich, St. Louis, USA) with the following specifications: a $100-380$ bp product size, a Tm (melting temperature) of $55-65{ }^{\circ} \mathrm{C}$, primer length of $18-26 \mathrm{bp}$, and absence of secondary structure when possible.

\section{LAMP assay and conventional PCR end point optimization}

Real-time LAMP. The real-time LAMP reactions were performed using the Isothermal Master Mix (ISO-001) produced by OptiGene Limited (Horsham, UK) on a CFX96 thermocycler. Each isothermal reaction was performed in duplicate, in a final volume of $20 \mu \mathrm{L}$ and using $2 \mu \mathrm{L}$ of DNA. Negative controls (NTC-no template control) were included for each reaction. At the end of the LAMP reactions, a melting curve was generated by increasing the temperature from 65 to $95{ }^{\circ} \mathrm{C}$ with a 10 -s interval every $0.5^{\circ} \mathrm{C}$ (Abdulmawjood et al. 2014). In real-time LAMP amplification, raw data were analyzed using CFX Maestro v. 1.0 (Biorad, Berkeley, CA, USA). Real-time LAMP products were checked on a $1.7 \%$ agarose gel stained with Gel Red (Biotium, Fremont, CA, USA).

The LAMP protocol optimization considered the following variables: isothermal amplification time, primer concentration and annealing temperature through a thermal gradient. Once the LAMP reaction had been optimized, the reactions were carried out using a second portable thermocycler, Genie ${ }^{\circledR}$ II (Optigene, Ltd, Horsham, UK) to evaluate
Table 1 Aromia bungii-The loop mediated isothermal amplification (LAMP) method primers designed in this study. For each primer, the nucleotide position related the the reference sequence is reported. The product sizes are $254 \mathrm{bp}(\mathrm{F} 3-\mathrm{B} 3)$ and 165 bp (F2-B2). The reference sequence is KF737790.

\begin{tabular}{llll}
\hline Primer name & Length $(\mathrm{nt})$ & Sequence 5'-3' & Nucleotide position \\
\hline Abungii_F3 & 20 & CTGGAACTGGATGAACAGTT & $365-384$ \\
Abungii_B3 & 20 & AATGGCTCCTGCTAATACTG & $618-599$ \\
Abungii_FIP(F1c + F2) & $23+21$ & AATTAACGGCACCGAGGATTGAA & $490-468$ \\
& & CCATGGAGGATCTTCAGTAGA & $411-431$ \\
Abungii_BIP(B1c+B2) & $25+22$ & ACTGTTATTAATATGCGCCCTTCCG & $499-523$ \\
& & CTGTAATAACAACAGCTCACAC & $575-553$ \\
Abungii_LoopF & 25 & GAGATTCCTGCTAGATGAAGTCTAA & $467-443$ \\
Abungii_LoopB & 24 & GGATAAGTCCAGATCGTATACCTT & $524-547$ \\
\hline
\end{tabular}

their reproducibility.
The specificity of the primers was further tested using BLAST $^{\circledR}$ (Basic Local Alignment Search Tool: http://www.

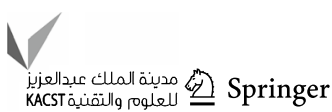




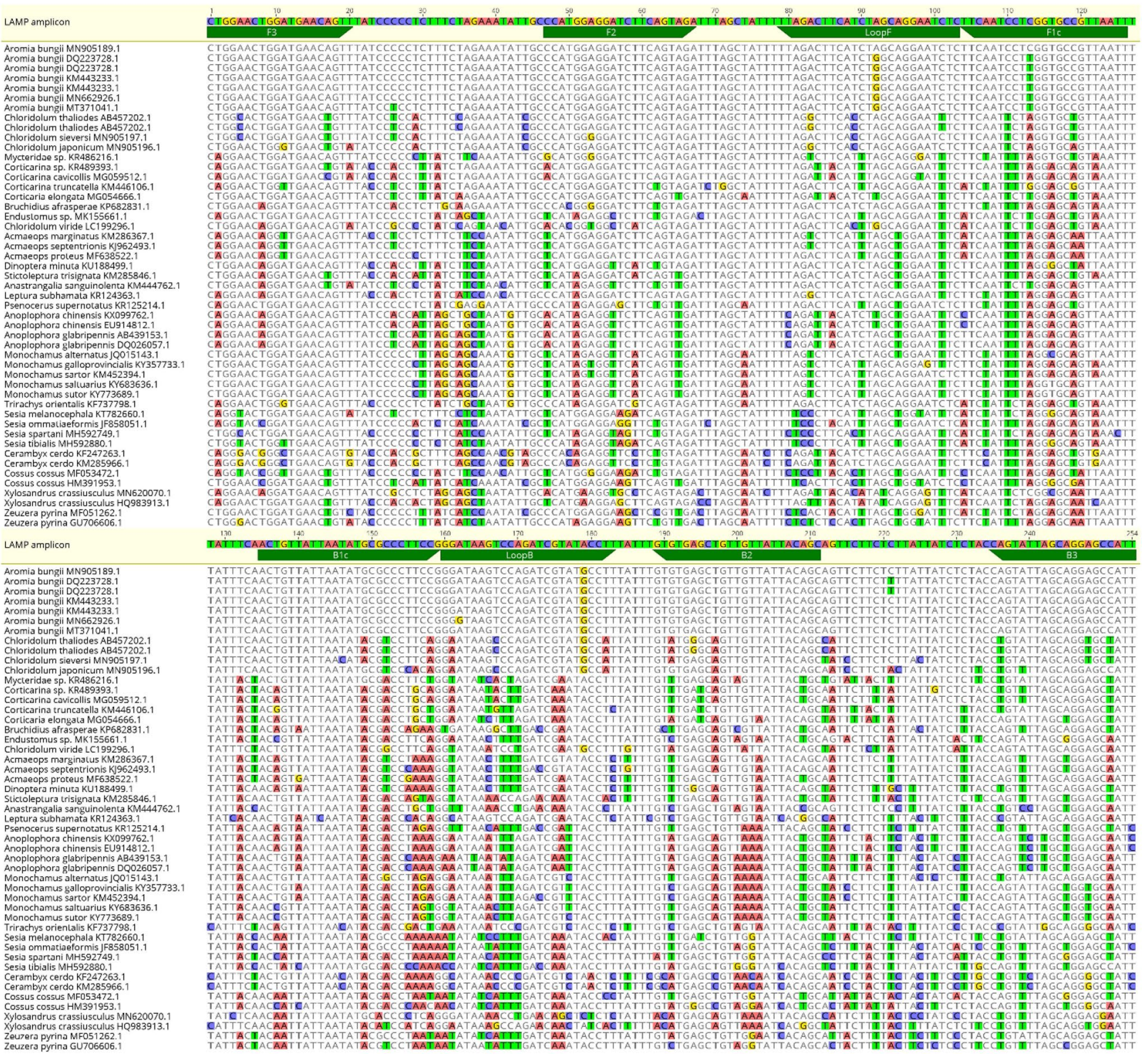

Fig. 2 Alignment of the LAMP amplicon of A. bungii and the sequences belonging to the most taxonomically related species (included the non-target xylophagous species used in the assays) present in GenBank. The reference sequence is the A. bungii LAMP

The optimal reaction mix for the real-time LAMP assay consisted of $10-\mu \mathrm{L}$ Isothermal Master Mix OptiGene (ISO001), $0.2 \mu \mathrm{M}$ of F3/B3, $0.4 \mu \mathrm{M}$ of LoopF/LoopB, $0.8 \mu \mathrm{M}$ of FIP/BIP and $2 \mu \mathrm{L}$ of template DNA $(5 \mathrm{ng} / \mu \mathrm{L})$ in a final volume of $20 \mu \mathrm{L}$. The melting peak for A. bungii samples was $83.5 \pm 0.5^{\circ} \mathrm{C}$ (Fig. 3).

Visual LAMP. To develop an alternative and easy-to-use protocol to detect the $A$. bungii DNA from collected samples, a visual LAMP approach based on the primers designed for the real-time LAMP assay was also tested. The Bst 3.0 DNA polymerase kit (New England Biolabs Ltd., UK) was amplicon (yellow areas); the correspondent primers are reported in blue. The nucleotides which differ from the reference sequence are highlighted with different colors according to the specific base

used for LAMP reactions on A. bungii DNA from frass with the same six LAMP primers used in the real-time LAMP test. Hydroxynaphthol Blue (HNB) was included in the reaction mixture (Goto et al. 2009) and the color change (from purple to blue) was evaluated at the end of the reaction.

To optimize the visual assay conditions, the same parameters considered for the real-time LAMP were assessed. The following reagents were optimized in their quantities and/ or concentrations: buffer, dNTPs, Betaine, MgSO4, HNB and primer concentration and Bst 3.0 DNA polymerase. The reaction was performed at $65^{\circ} \mathrm{C}$ for $30 \mathrm{~min}$, followed by an 
Table 2 Basic parameters of the methods compared to the LAMP assay

\begin{tabular}{|c|c|c|c|c|c|}
\hline Primers & Sequence $\left(5^{\prime}-3^{\prime}\right)$ & Length (bp) & $\begin{array}{l}\text { Anneal- } \\
\text { ing }\left({ }^{\circ} \mathrm{C}\right)\end{array}$ & Protocol & Reference \\
\hline Abungii_F3 & (Outermost primers of LAMP protocols in this study) & 254 & 60 & End-point PCR & This study \\
\hline Abungii_B3 & & & & qPCR SYBR Green & This study \\
\hline Abungii_285_F & CAGCAGTTCTTCTTTTATTATC & 199 & 58 & qPCR Probe & Rizzo et al. (2020a) \\
\hline Abungii_484_R & GGTGTCCAAAGAATCAAA & & & & \\
\hline Abungii_309_P & FAM-TACCAGTATTAGCAGGAGCCATTACG-BHQ1 & & & & \\
\hline Abungii_436F & TAACTTCCGTCTATTAGATGTA & 157 & 55 & qPCR SYBR Green & Rizzo et al. (2020a) \\
\hline Abungii_592R & GCTAACTTGGTTGATTCG & & & & \\
\hline Abungii_51_F & TCTATACTTTATCTTCGGTGCATGA & 318 & 55 & End-point PCR & This study \\
\hline Abungii_368_R & CCAGCACCCCTTTCTACGATT & & & & \\
\hline Abungii_28_F & ACCAACCATAAAGATATTGGAACTC & 462 & 54 & End-point PCR & This study \\
\hline Abungii_489_R & ATTAACGGCACCGAGGATTGA & & & & \\
\hline
\end{tabular}
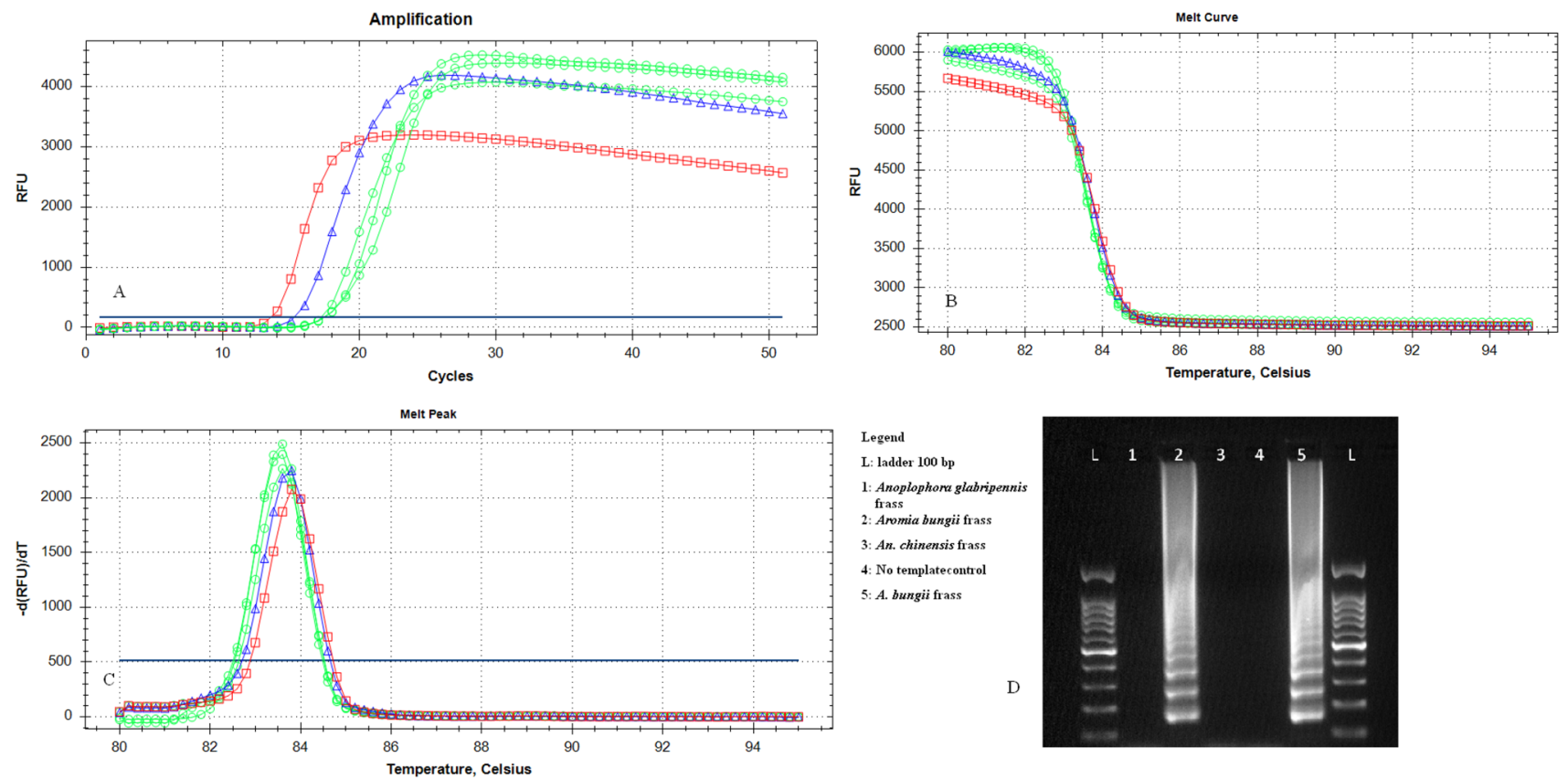

Fig. 3 Real-time LAMP amplification curves (a) and melting curve (b) and peak (c) from larva (squares), adult (triangles), and frass (circles) of Aromia bungii and NTC (no template control) (diamonds); d agarose gel showing the amplification product

additional cycle of $80{ }^{\circ} \mathrm{C}$ for 2 min. Isothermal amplifications were analyzed with a QIAxcel Capillary Electrophoresis System (QIAgen, Valencia, CA, USA) with the inclusion of a $25 \mathrm{bp}$ DNA marker. The QIAxcel system uses ScreenGel software, which determines the base pair number of each amplicon in individual amplification reactions.

The 20- $\mu \mathrm{L}$ optimal visual LAMP reaction mixture consisted of $2 \mu \mathrm{L}$ of Isothermal Buffer 10X, $0.6 \mathrm{mM}$ of dNTPs, $2 \mathrm{mM}$ of $\mathrm{MgSO}_{4}, 0.15 \mathrm{mM}$ of $\mathrm{HNB}, 0.2 \mathrm{M}$ of Betaine, 0.32 $\mathrm{U} / \mu \mathrm{L}$ of Bst 3.0 and final concentrations of the LAMP primers equal to $0.2 \mu \mathrm{M}$ for $\mathrm{F} 3 / \mathrm{B} 3,0.4 \mu \mathrm{M}$ for LoopF/LoopB, $0.8 \mu \mathrm{M}$ for FIP/BIP. $2 \mu \mathrm{L}$ of DNA template $(5 \mathrm{ng} / \mu \mathrm{L})$ was considered. The visual LAMP protocol was carried out on A. bungii and non-target DNA from frass of An. chinensis, An. glabripennis and C. cossus (Fig. 4).

Conventional PCR. The conventional PCR reactions were performed in $20-\mu \mathrm{L}$ reaction volumes containing $1 \mathrm{X}$ Master Mix PerfectTaq Hot Start 5Prime (Eppendorf, Milan, Italy), 0.4- $\mu \mathrm{M}$ forward and reverse primers, and $2 \mu \mathrm{L}$ of DNA template in a MyCycler thermocycler (Biorad, Berkeley, CA, USA). Cycling conditions consisted of $3 \mathrm{~min}$ at $94^{\circ} \mathrm{C}$, followed by 40 cycles of $94{ }^{\circ} \mathrm{C}$ for $30 \mathrm{~s}$, annealing (see Table 2) for $30 \mathrm{~s}$ and $72{ }^{\circ} \mathrm{C}$ for $45 \mathrm{~s}$, with a final extension step of 7 min at $72{ }^{\circ} \mathrm{C}$. PCR products were visualized on a $1.7 \%$ 


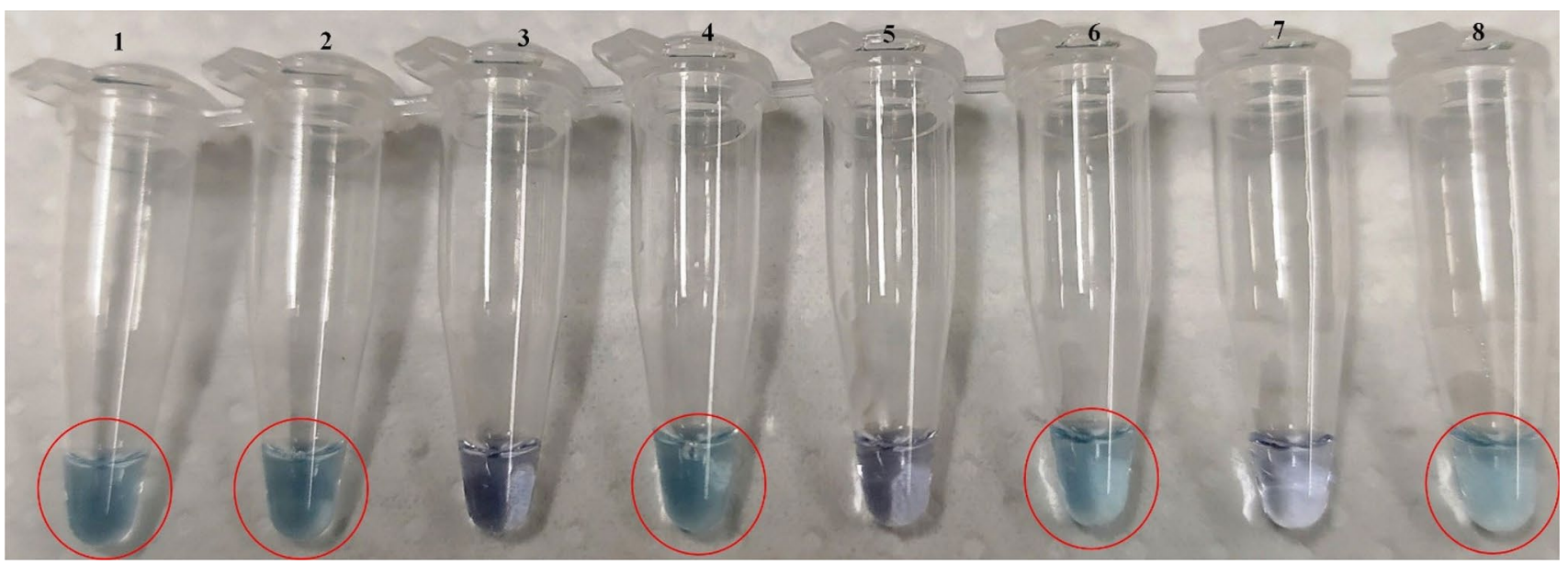

Fig. 4 Visual LAMP reaction tubes visualized by means of HNB (Hydroxynaphthol Blue) coloration. Positive samples are blue, and negative are purple. The assay was performed on DNA extracted from (left to right): tubes 1 and 2, Aromia bungii larvae; tube 3, Ano-

agarose gel using a $10-\mu \mathrm{L}$ aliquot of PCR reaction or using a QIAxcel Capillary Electrophoresis System.

\section{Performance characteristics of the LAMP assay}

Sensitivity, specificity and accuracy of the real-time and visual LAMP assays were evaluated after the optimization of the LAMP protocols on DNA samples of target and nontarget species (62 samples belonging to 26 species). Samples with a time amplification value (Tamp, min:s) (Aglietti et al. 2019) greater than 30 min were not considered. In the visual LAMP, the diagnostic specificity was verified by the naked eye assessing the color change of the reaction mixture. These parameters were calculated according to the EPPO standards on diagnostics PM7/76-4 (EPPO 2017) and PM7/98-4 (EPPO 2019).

\section{Blind panel validation of the assays}

A blind panel test was performed on six frass samples of $A$. bungii, two of Anoplophora chinensis, two of An. glabripennis and two of $C$. cossus. The test was carried out in two different laboratories (IPSP-CNR, Sesto Fiorentino, Italy and the Laboratory of the Plant Protection Service of Tuscany, Pistoia, Italy) applying the above-mentioned LAMP (real-time and visual) protocols. All DNA samples had been diluted at a final concentration of $5 \mathrm{ng} / \mu \mathrm{L}$. Samples were tested in duplicate; negative controls (NTC-no template control) were included. Based on the blind panel results, the true positives, false negatives, false positives and true negatives were evaluated according to the EPPO requirements outlined in PM7/76-4 (EPPO, 2017) and PM7/98-4 (EPPO 2019). plophora chinensis frass; tube 4, A. bungii frass; tube 5, An. glabripennis frass; tube 6, Aromia bungii frass, tube 7,C. cossus frass and tube $8, A$. bungii frass. The circles show the tubes containing $A$. bungii samples

\section{Repeatability and reproducibility}

The repeatability and reproducibility tests were carried out on ten samples of $A$. bungii DNA extracted from frass. The intra-run variation (repeatability) and inter-run variation (reproducibility) were estimated by standard parameters, such as the average Tamp and standard deviation (SD). Ten samples in triplicate, diluted to a final concentration of $5 \mathrm{ng} /$ $\mu \mathrm{L}$, were tested in two separate series for repeatability. The reproducibility of each protocol was assessed in the same way as carried out for the repeatability by comparing the data of two series of samples by two different operators on different days (Dhami et al. 2016; Koohkanzade et al. 2018).

\section{Limit of detection (LoD)}

For each methodology used in the experimental design, LoD was estimated using a tenfold 1:4 serial dilution using an "artificial" frass DNA (100 $\mathrm{ng} / \mu \mathrm{L})$, obtained by adding frass of another species (An. glabripennis, in this case) with $10 \mathrm{ng} / \mu \mathrm{L}$ of $A$. bungii DNA from larvae. All experiments were conducted in triplicate. To evaluate the influence of the initial matrix in defining the analytical sensitivity of the method under examination, the LoD verified with pure larva DNA extract and DNA extract from A. bungii artificial frass were compared. The comparison between the LoDs of the end point PCR and LAMP protocol was carried out by electrophoretic runs in $1.7 \%$ agarose gel stained with Gel Red (Biotium Inc., Fremont, CA, USA). In parallel, a QIAxcel Capillary Electrophoresis System (QIAgen, Valencia, CA, USA) was used with the inclusion of a 25-bp DNA marker. 


\section{Comparison with conventional PCR and qPCR (SYBR Green)}

To compare the sensitivity and performance of the assay, frass was used as the matrix with other molecular techniques, traditional end point PCR and qPCR (both hydrolysis probe and SYBR Green), performed with the parameters reported in Table 2.

The F3 and B3 primers, which are "external" to the ones used in the LAMP assay, were used in both conventional PCR and in qPCR SYBR Green.

\section{Results}

\section{Nucleic acid extractions from frass and insects}

The amplifiability of the DNA extracted from target and non-target frass samples (Table 3) gave satisfactory results. The Tamp average value of COX gene (LAMP protocol) was $12.3 \pm 2.4$ (min). The verification of amplifiability with the qPCR probe on insect extracts showed average values of $\mathrm{Cq}$ equal to $18.64 \pm 3.6$.

\section{Diagnostic sensitivity, specificity, and accuracy of the LAMP assay}

None of the tests carried out on target and non-target samples showed any non-specific amplification, and only $A$. bungii produced amplification curves. A unique peak at $83.5 \pm 0.5^{\circ} \mathrm{C}$, resulting from the melting curve analysis, was visualized for each $A$. bungii sample, regardless of the starting matrix and confirming the specificity of the real-time LAMP assay. In the case of the visual LAMP assay, only $A$. bungii samples (adult, larvae, and frass) were detected by the LAMP reaction, while none of the non-target samples (62 samples) was amplified. For both protocols, diagnostic sensitivity, diagnostic specificity, and relative accuracy were $100 \%$.

Table 3 Quantification of DNA extract from frass of Aromia bungii and non-target frass samples

\begin{tabular}{lcc}
\hline Species & $\begin{array}{c}\text { DNA concentration } \\
(\mathrm{ng} / \mu \mathrm{L})(\text { mean } \pm \mathrm{SD})\end{array}$ & $\begin{array}{l}A_{260 / \mathrm{A} 280} \text { ratio } \\
(\text { mean } \pm \mathrm{SD})\end{array}$ \\
\hline Aromia bungii & $85.10 \pm 4.00$ & $1.94 \pm 0.16$ \\
Anoplophora chinensis & $101.02 \pm 2.60$ & $1.84 \pm 0.14$ \\
Anoplophora glabripennis & $94.14 \pm 5.20$ & $1.82 \pm 0.18$ \\
Cerambyx cerdo & $76.56 \pm 2.30$ & $1.76 \pm 0.20$ \\
Cossus cossus & $89.24 \pm 2.30$ & $1.86 \pm 0.11$ \\
Sesia spp. & $68.63 \pm 3.20$ & $2.01 \pm 0.17$ \\
Zeuzera pyrina & $62.25 \pm 2.90$ & $1.88 \pm 0.18$ \\
\hline
\end{tabular}

The end point PCR protocols designed to compare the analytical sensibility (LoD) were also assayed on the same target and non-target samples, showing a diagnostic specificity of $100 \%$, as in the LAMP assay developed in this study.

\section{Blind panel validation of the assay}

The blind panel test performed using the real-time and visual LAMP protocols showed the amplification only of the A. bungii frass samples, with a mean Tamp value equal to $18.21 \pm 0.42 \mathrm{~min}$ in the case of real-time LAMP, whereas the non-target frass samples were not amplified. The specificity, sensitivity and accuracy of the data were $100 \%$. In both laboratories, the results obtained with real-time and visual LAMP were the same. Only the A. bungii frass samples amplified, whereas there was no amplification of the DNA samples extracted from the frass of the xylophagous species used as comparison (non-target frass samples).

\section{Repeatability and reproducibility of the diagnostic methods}

In terms of repeatability, the Tamp values varied from 10.12 to $13.30 \mathrm{~min}$ with a mean value of $10.90 \pm 1.20 \mathrm{~min}$, and an average CV\% of 11.04 .

The standard deviation (SD) of the two replicates of the same protocol ranged between 0.06 and 3.65. In terms of reproducibility, the values ranged between 0.10 and 7.24 (Table 4).

\section{Limit of detection (LoD) of the LAMP assay and comparison with conventional PCR and qPCR}

The LoD was obtained both for the real-time LAMP assay and for the visual LAMP. For the real-time assay, the LoD was $0.61 \mathrm{pg} / \mu \mathrm{L}$, with a Tamp value of $24.36 \pm 0.90 \mathrm{~min}$. For the visual LAMP assay, the LoD was the same as for the real-time LAMP assay.

Table 5 compares the LoD values obtained in the different techniques. The data assigned to the PCR protocols (probe for hydrolysis and SYBR Green) (Rizzo et al. 2020a), have been omitted in this table.

Figures 5 and 6 show the results of the electrophoretic runs carried out to compare the LoDs of the conventional PCR (end point) and LAMP, using 1.7\% agarose gel stained with Gel Red and QIAxcel Capillary Electrophoresis System (Qiagen, Valencia, CA, USA), respectively.

The comparison of the analytical sensitivity according to the starting matrix (larva and artificial frass) provided the data shown in Table 6. 
Table 4 Repeatability and reproducibility of real-time assays evaluated as $\mathrm{Cq} \pm \mathrm{SD}$ values

\begin{tabular}{llll}
\hline Sample & \multicolumn{2}{l}{ Real-time LAMP amplification } \\
\cline { 2 - 3 } & \multicolumn{2}{l}{ Repeatability } & Reproducibility \\
\cline { 2 - 3 } & Assay 1 & Assay 2 & \\
\hline 1 & $17.37 \pm 0.06$ & $16.48 \pm 1.20$ & $16.52 \pm 1.26$ \\
2 & $19.12 \pm 0.66$ & $18.09 \pm 2.13$ & $17.62 \pm 1.46$ \\
3 & $24.28 \pm 3.65$ & $19.16 \pm 3.59$ & $21.74 \pm 7.24$ \\
4 & $18.85 \pm 0.65$ & $18.60 \pm 0.29$ & $19.06 \pm 0.36$ \\
5 & $17.77 \pm 2.03$ & $17.36 \pm 1.45$ & $18.79 \pm 0.58$ \\
6 & $17.41 \pm 0.83$ & $17.58 \pm 0.59$ & $16.99 \pm 0.24$ \\
7 & $16.74 \pm 1.25$ & $16.29 \pm 0.62$ & $17.18 \pm 0.63$ \\
8 & $18.58 \pm 2.18$ & $16.57 \pm 1.52$ & $18.11 \pm 0.66$ \\
9 & $16.87 \pm 2.05$ & $16.28 \pm 1.22$ & $17.73 \pm 0.83$ \\
10 & $17.66 \pm 0.83$ & $17.59 \pm 0.74$ & $18.18 \pm 0.10$ \\
\hline
\end{tabular}

\section{Discussion}

Molecular tools for identifying quarantine insect pests are essential for managing outbreaks, especially in view of the setup of international shared diagnostic protocols (Augustin et al. 2012). Of these molecular methods, the LAMP technique (Tani et al. 2007; Tomlinson et al. 2010a; Moradi et al. 2014; Blaser et al. 2018; Panno et al. 2020) can be used for a direct diagnosis of insect specimens (adults or larvae), as well as for an indirect analysis of insect DNA present in residues deriving from the trophic activity (e.g., frass as in Kyei-Poku et al. 2020).

For frass samples, three critical points must be considered: (a) the paucity of insect DNA in these samples; (b) the presence of amplification inhibitors deriving from frass (Mitchell and Hanks 2009; Schrader et al. 2012; Strangi et al. 2013; Nagarajan et al. 2020; Rizzo et al. 2020a, b); and (c) the possibility DNA degradation over time or as an effect of frass exposition to environmental factors.

We used the LAMP method on A. bungii frass. Our results show that all three issues (a-c above) were overcome. In all samples, the DNA quantity was always suitable and amplifiable for the LAMP reactions, managing the co-extraction of inhibitors from the frass samples, and with an $\mathrm{A}_{260 / 280}$ ratio of between 1.8 and 2.0. However, the DNA amount extracted from adults and larvae of $A$. bungii was higher than in the frass samples, but with a higher variability in terms of concentration, probably related to the specimen size.

Our real-time LAMP protocol on frass gave good results in terms of specificity, especially given that Aromia moschata, a native species taxonomically related to A. bungii included in the non-target species assayed, did not respond to the amplification reaction (Rizzo et al. 2020a). The protocol was also sensitive and accurate, and overall, the reaction demonstrated its robustness when the test was performed on different thermocyclers and with different operators. The repeatability and reproducibility data showed SD values with a relatively high range (Teter and Steffen 2020), of
Table 5 LoD assay based on artificial frass of Aromia bungii using $1: 4$ serial dilutions (ranging from $10 \mathrm{ng} / \mu \mathrm{L}$ to $2.38 \mathrm{fg} / \mu \mathrm{L}$ ) and the real-time LAMP protocol. For each dilution different PCR methods were evaluated. The average $\mathrm{Cq} / \mathrm{Tamp} \pm$ standard deviation (SD) was equal to the average of the three threshold cycles of each dilution $(\mathrm{Cq} /$
Tamp) \pm SD. In the case of qPCR, Cq values above 35 were considered as negative results. (1) PCR end point (F3/B3, this study); (2) PCR end point (28F/489R, this study); (3) qPCR SYBR Green (F3/ B3 this study). The \pm symbol in the visual LAMP column indicates an uncertain result

\begin{tabular}{|c|c|c|c|c|c|}
\hline \multirow[t]{3}{*}{ Dilutions 1:4 } & \multicolumn{5}{|l|}{ Diagnostic method } \\
\hline & Real-time LAMP & Visual LAMP & PCR end point (1) & PCR end point (2) & qPCR SYBR Green (3) \\
\hline & $\begin{array}{l}\text { Tamp (min:s) } \\
\text { mean } \pm \text { SD }\end{array}$ & $\begin{array}{l}\text { Positive }(+) / \text { negative } \\
(-)\end{array}$ & $\begin{array}{l}\text { Positive }(+) / \text { negative } \\
(-)\end{array}$ & Positive (+)/negative (-) & $\mathrm{Cq}$ means $\pm \mathrm{SD}$ \\
\hline $10 \mathrm{ng} / \mu \mathrm{L}$ & $14.22 \pm 1.49$ & + & + & + & $18.99 \pm 0.84$ \\
\hline $2.50 \mathrm{ng} / \mu \mathrm{L}$ & $15.24 \pm 1.68$ & + & + & + & $21.02 \pm 0.31$ \\
\hline $0.62 \mathrm{ng} / \mu \mathrm{L}$ & $16.59 \pm 1.88$ & + & + & + & $22.82 \pm 0.76$ \\
\hline $0.16 \mathrm{ng} / \mu \mathrm{L}$ & $18.59 \pm 1.38$ & + & + & + & $24.60 \pm 0.54$ \\
\hline $0.04 \mathrm{ng} / \mu \mathrm{L}$ & $21.53 \pm 3.07$ & + & + & + & $26.93 \pm 0.16$ \\
\hline $9.76 \mathrm{pg} / \mu \mathrm{L}$ & $23.99 \pm 0.73$ & + & - & - & $29.43 \pm 0.25$ \\
\hline $2.44 \mathrm{pg} / \mu \mathrm{L}$ & $26.84 \pm 1.76$ & + & - & - & $32.31 \pm 0.28$ \\
\hline $0.61 \mathrm{pg} / \mu \mathrm{L}$ & $24.36 \pm 0.90$ & \pm & - & - & $33.44 \pm 0.07$ \\
\hline $0.15 \mathrm{pg} / \mu \mathrm{L}$ & - & - & - & - & - \\
\hline $38.14 \mathrm{fg} / \mu \mathrm{L}$ & - & - & - & - & - \\
\hline $9.53 \mathrm{fg} / \mu \mathrm{L}$ & - & - & - & - & - \\
\hline $2.38 \mathrm{fg} / \mu \mathrm{L}$ & - & - & - & - & - \\
\hline
\end{tabular}




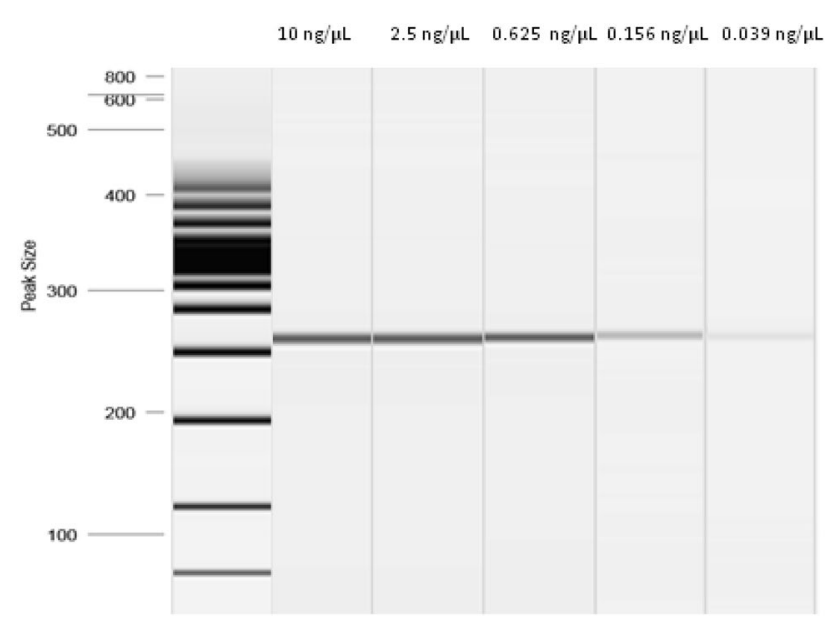

Fig. 5 Electrophoresis capillarity with QIAxcel Capillary Electrophoresis System (Qiagen, Valencia, CA, USA). PCR end point with primers F3 and B3 on serial dilution 1:4 from frass artificial of Aromia bungii. The marker ranged from 25 to 3000 bp (Qiagen, Valencia, CA, USA) variability (presumably due to the presence of a high quantity of PCR inhibitors in frass).

The use of LAMP based on a naked-eye detection system to determine the amplification result is becoming a routine approach in molecular diagnosis (Blaser et al. 2018). Our visual LAMP is a further simplification of the real-time LAMP technology as it does not require sophisticated instruments (which entail large investments, skilled personnel, and high management costs), is rapid, specific, sensitive and with a good accuracy, also compared to real-time LAMP. In addition, the limits of detection are identical to those of real-time LAMP (LoD of $0.61 \mathrm{pg} / \mu \mathrm{L}$ for the proposed techniques).

The analytical sensitivity of the LAMP (LoD) test compared with conventional PCR (28F/489R and 51F/368R) was more sensitive $\left(>10^{3}\right)$ to the same starting matrix. The results show that LAMP assays and qPCR SYBR Green method (using the F3/B3 LAMP external primers) are equally sensitive, and they are more sensitive than conventional PCR.

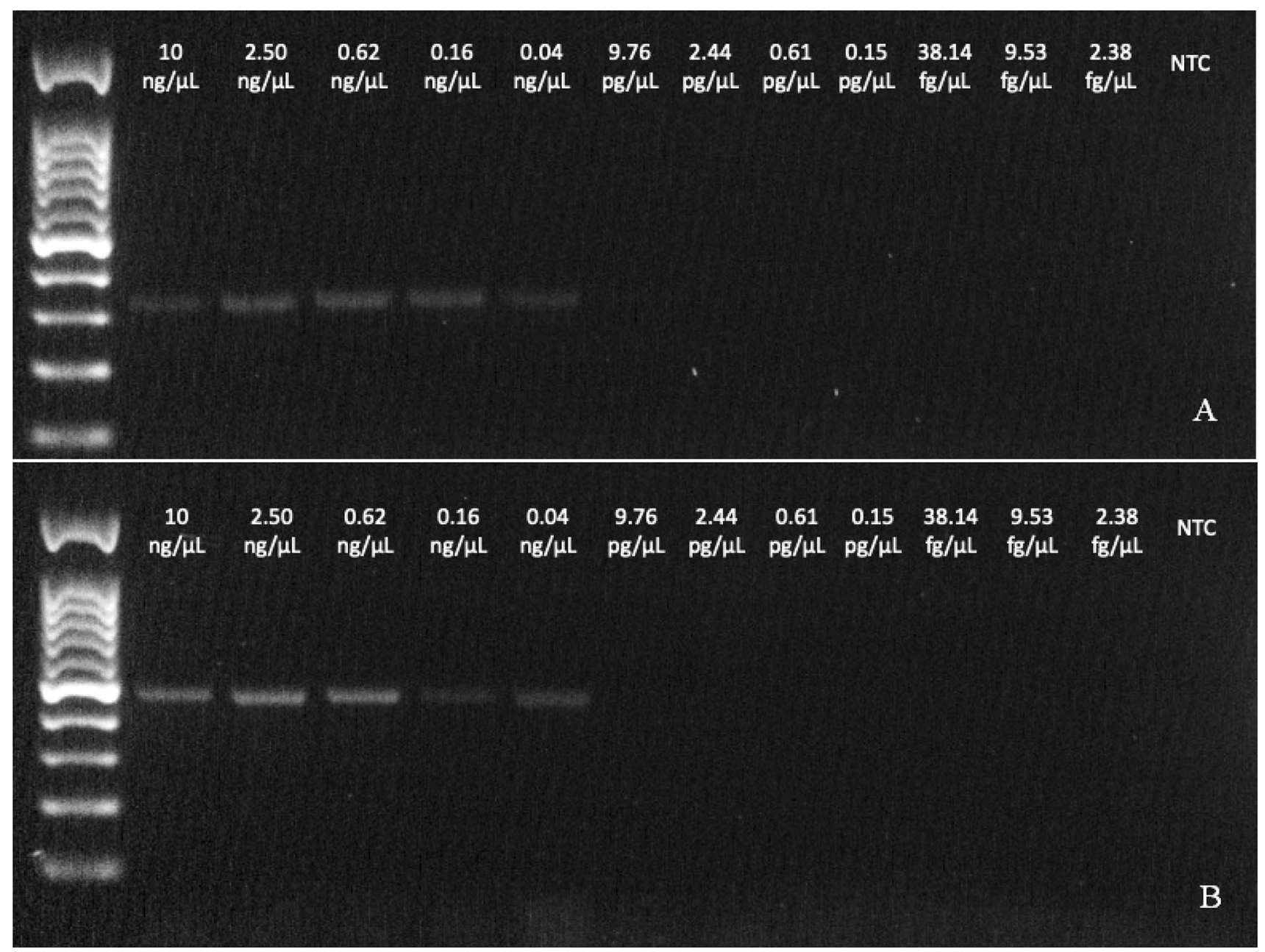

Fig. 6 Agarose gels for PCR end point with 51F/368R primers (a) and with 28F/489R primers (b) on serial dilution 1:4 from artificial frass of Aromia bungii. The ladder weight was 100 bp (Genespin, Milan, Italy) 
Table 6 Analytical sensitivity (LoD) between 1:4 serial dilutions of Aromia bungii larva DNA extract (10 ng-2.38 fg/ $\mu \mathrm{L})$ and 1:4 serial dilutions of Anoplophora glabripennis artificial frass extract to which

\begin{tabular}{|c|c|c|c|c|}
\hline \multirow[t]{3}{*}{ Dilutions 1:4 } & \multicolumn{2}{|c|}{ DNA extract from A. bungii larva } & \multicolumn{2}{|c|}{ DNA extract from An. glabripennis artificial frass } \\
\hline & Real-time LAMP & Visual LAMP & Real-time LAMP & Visual LAMP \\
\hline & Tamp (min:s) avg $\pm \mathrm{SD}$ & Positive (+)/negative (-) & Tamp (min:s) avg \pm SD & Positive $(+) /$ negative $(-)$ \\
\hline $10 \mathrm{ng} / \mu \mathrm{L}$ & $14.62 \pm 0.34$ & + & $14.22 \pm 1.49$ & + \\
\hline $2.50 \mathrm{ng} / \mu \mathrm{L}$ & $14.77 \pm 1.81$ & + & $15.24 \pm 1.68$ & + \\
\hline $0.62 \mathrm{ng} / \mu \mathrm{L}$ & $16.07 \pm 0.15$ & + & $16.59 \pm 1.88$ & + \\
\hline $0.16 \mathrm{ng} / \mu \mathrm{L}$ & $16.12 \pm 1.30$ & + & $18.59 \pm 1.38$ & + \\
\hline $0.04 \mathrm{ng} / \mu \mathrm{L}$ & $16.79 \pm 0.81$ & + & $21.53 \pm 3.07$ & + \\
\hline $9.76 \mathrm{pg} / \mu \mathrm{L}$ & $18.60 \pm 1.73$ & + & $23.99 \pm 0.73$ & + \\
\hline $2.44 \mathrm{pg} / \mu \mathrm{L}$ & $24.80 \pm 10.78$ & + & $26.84 \pm 1.76$ & + \\
\hline $0.61 \mathrm{pg} / \mu \mathrm{L}$ & $25.74 \pm 13.00$ & + & $24.36 \pm 0.90$ & + \\
\hline $0.15 \mathrm{pg} / \mu \mathrm{L}$ & $26.10 \pm 4.20$ & + & $\mathrm{n} / \mathrm{a}$ & - \\
\hline $38.14 \mathrm{fg} / \mu \mathrm{L}$ & $32.18 \pm 4.41$ & + & $\mathrm{n} / \mathrm{a}$ & - \\
\hline $9.53 \mathrm{fg} / \mu \mathrm{L}$ & $26.78 \pm 0.46$ & \pm & $\mathrm{n} / \mathrm{a}$ & - \\
\hline $2.38 \mathrm{fg} / \mu \mathrm{L}$ & $\mathrm{n} / \mathrm{a}$ & - & $\mathrm{n} / \mathrm{a}$ & - \\
\hline
\end{tabular}

$10 \mathrm{ng}$ of $A$. bungii larva extract was added. The \pm symbol in the A. bungii visual LAMP column indicates an uncertain result
The analytical sensitivity is affected by the matrix investigated. This was clear when the LoD of a DNA extract from $A$. bungii larva serially diluted 1:4 (from $10 \mathrm{ng} / \mathrm{L}$ to $2.38 \mathrm{fg} / \mu \mathrm{L}$ ) was compared with the values resulting from the LoD of the LAMP assay on $A$. bungii 's artificial frass. The LAMP test studied was $10^{3}$ (from $0.61 \mathrm{pg} / \mathrm{l}$ to $9.53 \mathrm{fg} / \mu \mathrm{L}$ ) more sensitive from the "pure" matrix of $A$. bungii larva than the corresponding artificial frass. These values confirm that the starting matrix is difficult to extract and amplify, but at the same time indicate the excellent performance of our LAMP assay.

A comparison of the data resulting from similar studies (Rizzo et al. 2020a), clearly show the greater analytical sensitivity of our new LAMP approach.

Although LAMP is a powerful method for the screening of samples and rapid responses, it may not be suitable when many validation parameters need to be estimated, as in the case of intra- or inter-lab comparisons (Panno et al. 2020). Moreover, the LAMP reaction is more prone to cross-contamination than other amplification techniques (Karami et al. 2011; Karthik et al. 2014).

The rapidity (less than $2 \mathrm{~h}$ ) of our tests and, in the case of visual LAMP, the cheapness of the proposed protocols suggest their potential in the near future for preventing or managing outbreaks of $A$. bungii in areas with a high risk of introduction, especially if integrated with other monitoring tools such as pheromone or allelochemical traps. A decisive enhancement for making the method simpler to apply also in the field, could be a simplification of the DNA extraction from the frass matrix using a crude extract.

\section{Conclusions}

The efficient management of a quarantine insect pest is based on detecting outbreaks as quickly as possible. Among the molecular methods, LAMP is a promising tool and more simple than the classical morphological approach, which requires intact samples and highly specialized skills. This is particularly true for xylophagous insects, where the sample collection is onerous in terms of time and costs, but also difficult due to the endophytic life of the preimaginal stages.

Acknowledgements The authors wish to thank the staff of the Phytosanitary Service of Campania Region for the help in the field collection of the samples.

Author contributions Conceptualization of the research approach, detailed laboratory methodologies, and experimental designs for this study were developed and conducted by DR (principal investigator) with the assistance of NL, DDL, and ER. All field works were carried out by RVG, APG, GC, TB, and FN. All sample preparations, data collection and statistical analyses of data collected from DNA extracts to LAMP were completed by DR, DDL, CS, NL and ER. Data curation and data mining, reference assembly and manuscript formatting were done by DR, NL, APG, FN, and ER. This paper was originally drafted by DR, DDL, ER, FN, NL, and APG. The manuscript was revised and edited by all the authors.

Funding Open Access funding provided by Università di Pisa.

\section{Compliance with ethical standards}

Conflict of interest The authors declare no conflict of interest. 
Ethical approval This article does not contain any studies with human participants or animals (vertebrates) performed by any of the authors.

Open Access This article is licensed under a Creative Commons Attribution 4.0 International License, which permits use, sharing, adaptation, distribution and reproduction in any medium or format, as long as you give appropriate credit to the original author(s) and the source, provide a link to the Creative Commons licence, and indicate if changes were made. The images or other third party material in this article are included in the article's Creative Commons licence, unless indicated otherwise in a credit line to the material. If material is not included in the article's Creative Commons licence and your intended use is not permitted by statutory regulation or exceeds the permitted use, you will need to obtain permission directly from the copyright holder. To view a copy of this licence, visit http://creativecommons.org/licenses/by/4.0/.

\section{References}

Abdulmawjood A, Grabowski N, Fohler S, Kittler S, Nagengast H, Klein G (2014) Development of loop-mediated isothermal amplification (LAMP) assay for rapid and sensitive identification of ostrich meat. PLoS ONE 9:e100717. https://doi.org/10.1371/journ al.pone. 0100717

Aglietti C, Luchi N, Pepori AL, Bartolini P, Pecori F, Raio A, Capretti P, Santini A (2019) Real-time loop-mediated isothermal amplification: an early-warning tool for quarantine plant pathogen detection. AMB Expr 9:50. https://doi.org/10.1186/s13568-019-0774-9

Altschul S, Gish W, Miller W, Myers EW, Lipman DJ (1990) Basic local alignment search tool. J Mol Biol 215:403-410. https://doi. org/10.1016/S0022-2836(05)80360-2

Augustin S, Boonham N, De Kogel WJ, Donner P, Faccoli M, Lees DC, Marini L, Mori N, Toffolo EP, Quilici S, Roques A, Yart A, Battisti A (2012) A review of pest surveillance techniques for detecting quarantine pests in Europe. Bull OEPP 42(3):515-551. https://doi.org/10.1111/epp.2600

Blaser S, Diem H, von Felten A, Gueuing M, Andreou M, Boonham N, Tomlinson J, Müller P, Utzinger J, Frey JE, Bühlmann A (2018) From laboratory to point of entry: development and implementation of a LAMP-based genetic identification system to prevent introduction of quarantine insect species. Pest Manag Sci 74:1504-1512. https://doi.org/10.1002/ps.4866

CABI (2020) Aromia bungii. In Invasive Species Compendium; CAB International: Wallingford, UK. http://www.cabi.org/isc. Accessed 2 Mar 2020

Carella D (2019) Regional action plan for the control of the longhorn beetle Aromia bungii-VII update; Executive Decree n. 134. Bollettino Ufficiale della Regione Campania, Italy (in Italian)

Dhami MK, Dsouza M, Waite DW, Anderson D, Li D (2016) Real time PCR Assay for the Identification of the Brown Marmorated Stink Bug (Halyomorpha halys). Front Mol Biosci 3:5. https://doi. org/10.3389/fmolb.2016.00005

EFSA (European Food Safety Authority), de la Peña E, Schrader G, Vos S (2019) Pest survey card on Aromia bungii. EFSA supporting publication 2019:EN-1731. https://doi.org/10.2903/sp.efsa.2019. EN-1731

EPPO (European and Mediterranean Plant Protection Organization) (2017) PM 7/76 (4). Use of EPPO diagnostic protocols. Bull OEPP 47(1):7-9

EPPO (European and Mediterranean Plant Protection Organization) (2019) PM 7/98 (4). Specific requirements for laboratories preparing accreditation for a plant pest diagnostic activity. Bull OEPP 49(3):530-563
EPPO (European and Mediterranean Plant Protection Organization) (2020) EPPO Global Database, Aromia bungii (AROMBU). https ://gd.eppo.int/taxon/AROMBU/distribution. Accessed 18 Mar 2020

EU (2019) Commission Delegated Regulation (EU) 2019/1702 of 1 August 2019 supplementing regulation (EU) 2016/2031 of the European Parliament and of the council by establishing the list of priority pests. OJ L 260:8-10. http://data.europa.eu/eli/reg_ del/2019/1702/oj. Accessed 3 Mar 2020

Fekrat L, Zaki Aghl M, Tahan V (2015) Application of the LAMP assay as a diagnostic technique for rapid identification of Thrips tabaci (Thysanoptera: Thripidae). J Econ Entomol 108:13371343. https://doi.org/10.1093/jee/tov099

Goto M, Honda E, Ogura A, Nomoto A, Hanaki K (2009) Colorimetric detection of loop mediated isothermal amplification reaction by using hydroxy naphthol blue. Biotechniques 46:167-172. https:// doi.org/10.2144/000113072

Hörren T (2016) Ein weiterer Nachweis des asiatischen Moschusbocks Aromia bungii (Faldermann, 1835) in Deutschland (Coleoptera: Cerambycidae, Cerambycinae). Entomol Z 126(4): 205-207 (abstr in English)

Hsieh CH, Wang HY, Chen YF, Ko CC (2012) Loop-mediated isothermal amplification for rapid identification of biotypes B and $\mathrm{Q}$ of the globally invasive pest Bemisia tabaci and studying population dynamics. Pest Manag Sci 68:1206-1213. https:// doi.org/10.1002/ps.3298

Huang CG, Hsu JC, Haymer DS, Lin GC, Wu WJ (2009) Rapid identification of the Mediterranean fruit fly (Diptera: Tephritidae) by loop-mediated isothermal amplification. J Econ Entomol 102:1239-1246. https://doi.org/10.1603/029.102.0350

Ide T, Kanzaki N, Ohmura W, Okabe K (2016a) Molecular identification of an invasive wood-boring insect Lyctus brunneus (Coleoptera: Bostrichidae: Lyctinae) using frass by loop-mediated isothermal amplification and nested PCR assays. J Econ Entomol 109:1410-1414. https://doi.org/10.1093/jee/tow030

Ide T, Kanzaki N, Ohmura W, Okabe K (2016b) Molecular identification of the western drywood termite (Isoptera: Kalotermitidae) by loop-mediated isothermal amplification of DNA from fecal pellets. J Econ Entomol 109:2234-2237. https://doi. org/10.1093/jee/tow 167

Ioos R, Fourrier C, Iancu G, Gordon TR (2009) Sensitive detection of Fusarium circinatum in pine seed by combining an enrichment procedure with a real-time polymerase chain reaction using dual-labeled probe chemistry. Phytopathology 99:582590. https://doi.org/10.1094/PHYTO-99-5-0582

Karami A, Gill P, Motamedi MHK, Saghafinia M (2011) A review of the current isothermal amplification techniques: applications, advantages and disadvantages. J Glob Infect Dis 3(3):293-302. https://doi.org/10.4103/0974-777X.83538

Karthik K, Rathore R, Thomas P, Arun TR, Viswas KN, Dhama K, Agarwal RK (2014) New closed tube loop mediated isothermal amplification assay for prevention of product crosscontamination. MethodsX 1:137-143. https://doi.org/10.1016/j. mex.2014.08.009

Kearse M, Moir R, Wilson A, Stones-Havas S, Cheung M, Sturrock S, Buxton S, Cooper A, Markowitz S, Duran C, Thierer T, Ashton B, Meintjes P, Drummond A (2012) Geneious basic: an integrated and extendable desktop software platform for the organization and analysis of sequence data. Bioinformatics 28(12):1647-1649. https://doi.org/10.1093/bioinformatics/bts199

Kogovšek P, Hodgetts J, Hall J, Prezelj N, Nikolić P, Mehle N, Lenarčič R, Rotter A, Dickinson M, Boonham N, Dermastia M, Ravnikar M (2015) LAMP assay and rapid sample preparation method for on-site detection of flavescence doré phytoplasma in grapevine. Plant Pathol 64:286-296. https://doi.org/10.1111/ppa.12266

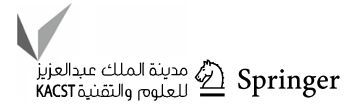


Koohkanzade M, Zakiaghl M, Dhami MK, Fekrat L, Namaghi HS (2018) Rapid identification of Bactrocera zonata (Dip.: Tephritidae) using TaqMan real time PCR assay. PLoS ONE 13(10):e0205136. https://doi.org/10.1371/journal.pone.0205136

Kyei-Poku G, Gauthier D, Quan G (2020) Development of a loopmediated isothermal amplification assay as an early-warning tool for detecting Emerald Ash Borer (Coleoptera: Buprestidae) incursions. J Econ Entomol toaa. https://doi.org/10.1093/jee/toaa135

Li R, Mocka R, Huang Q, Abad J, Hartung J, Kinarda G (2008) A reliable and inexpensive method of nucleic acid extraction for the PCR-based detection of diverse plant pathogens. J Virol Methods 154:48-55. https://doi.org/10.1016/j.jviromet.2008.09.008

Lucchi NW, Demas A, Narayanan J, Sumari D, Kabanywanyi A, Kachur SP, Barnewell JW, Udhayakumar V (2010) Real-time fluorescence loop mediated isothermal amplification for the diagnosis of malaria. PLoS ONE 5:e13733. https://doi.org/10.1371/journ al.pone. 0013733

Luchi N, Ioos R, Santini A (2020) Fast and reliable molecular methods to detect fungal pathogens in woody plants. Appl Microbiol Biotechnol. https://doi.org/10.1007/s00253-020-10395-4

Ma WH, Sun LY, Yu LG, Wang JT, Chen JY (2007) Study on the occurrence and life history in Aromia bungii (Faldermann). Acta Agric Boreali Sinica 22:247-249

Mitchell RF, Hanks LM (2009) Insect frass as a pathway for transmission of bacterial wilt of cucurbits. Environ Entomol 38(2):395403. https://doi.org/10.1603/022.038.0212

Moradi A, Almasi MA, Jafary H, Mercado-Blanco J (2014) A novel and rapid loop-mediated isothermal amplification assay for the specific detection of Verticillium dahliae. J Appl Microbiol 116(4):942-954. https://doi.org/10.1111/jam.12407

Nagarajan RP, Goodbla A, Graves E, Baerwald M, Holyoak M, Schreier A (2020) Non-invasive genetic monitoring for the threatened valley elderberry longhorn beetle. PLoS ONE 15(1):e0227333. https ://doi.org/10.1371/journal.pone.0227333

Notomi T, Mori Y, Tomita N, Kanda H (2015) Loop-mediated isothermal amplification (LAMP): principle, features, and future prospects. Res J Microbiol 53(1):1-5. https://doi.org/10.1007/ s12275-015-4656-9

Notomi T, Okayama H, Masubuchi H, Yonekawa T, Watanabe K, Amino N, Hase T (2000) Loop-mediated isothermal amplification of DNA. Nucleic Acids Res 28:e63. https://doi.org/10.1093/ nar/28.12.e63

Panno S, Matić S, Tiberini A, Caruso AG, Bella P, Torta L, Stassi R, Davino S (2020) Loop mediated isothermal amplification: principles and applications in plant virology. Plants 9(4):461. https:// doi.org/10.3390/plants9040461

Poland TM, Rassati D (2019) Improved biosecurity surveillance of non-native forest insects: a review of current methods. J Pest Sci 92:37-49. https://doi.org/10.1007/s10340-018-1004-y

Przybylska A, Fiedler Z, Kucharczyk H, Obrepalska-Steplowska A (2015) Detection of the quarantine species Thrips palmi by loop-mediated isothermal amplification. PLoS ONE 10:e0122033. https://doi.org/10.1371/journal.pone.0122033

Rizzo D, Taddei A, Da Lio D, Nugnes F, Barra E, Stefani L, Bartolini L, Griffo RV, Spigno P, Cozzolino L, Rossi E, Garonna AP (2020a) Identification of the Red-Necked Longhorn Beetle Aromia bungii (Faldermann, 1835) (Coleoptera: Cerambycidae) with real-time PCR on frass. Sustainability 12:6041. https://doi. org/10.3390/su12156041

Rizzo D, Taddei A, Da Lio D, Bruscoli T, Cappellini G, Bartolini L, Salemi C, Luchi N, Pennacchio F, Rossi E (2020b) Molecular Identification of Anoplophora glabripennis(Coleoptera: Cerambycidae) from frass by loop-mediated isothermal amplification. J Econ Entomol toaa. https://doi.org/10.1093/jee/toaa206

Russo E, Nugnes F, Vicinanza F, Garonna AP, Bernardo U (2020) Biological and molecular characterization of Aromia bungii (Faldermann, 1835) (Coleoptera: Cerambycidae), an emerging pest of stone fruits in Europe. Sci Rep 10:7112. https://doi.org/10.1038/ s41598-020-63959-9

Sabahi S, Fekrat L, Zakiaghl M, Moravej GH (2018) Loop-mediated isothermal amplification combined with PCR for rapid identification of the Ethiopian fruit fly (Diptera: Tephritidae). Neotrop Entomol 47:96-105. https://doi.org/10.1007/s13744-017-0522-2

Schrader C, Schielke A, Ellerbroek L, Johne R (2012) PCR inhibitors-occurrence, properties and removal. J Appl Microbiol 113(5):1014-1026. https://doi.org/10.111 1/j.1365-2672.2012.05384.x

Strangi A, Sabbatini Peverieri G, Roversi PF (2013) Managing outbreaks of the citrus long-horned beetle Anoplophora chinensis (Forster) in Europe: molecular diagnosis of plant infestation. Pest Manag Sci 69:627-634. https://doi.org/10.1002/ps.3416

Tani H, Teramura T, Adachi K, Tsuneda S, Kurata S, Nakamura K, Kanagawa T, Noda N (2007) Technique for quantitative detection of specific DNA sequences using alternately binding quenching probe competitive assay combined with loop-mediated isothermal amplification. Anal Chem 79(15):5608-5613. https://doi. org/10.1021/ac070041e

Teter S, Steffen L (2020) Real-time qPCR: guidelines for a comparison of reagent performance. Application note \#AN299. Promega Corporation

Tomlinson JA, Dickinson MJ, Boonham N (2010a) Detection of Botrytis cinerea by loop-mediated isothermal amplification. Lett Appl Microbiol 51(6):650-657. https://doi.org/10.1111/j.1472765X.2010.02949.x

Tomlinson JA, Dickinson MJ, Boonham N (2010b) Rapid detection of Phytophthora ramorum and P. kernoviae by two-minute DNA extraction followed by isothermal amplification and amplicon detection by generic lateral flow device. Phytopathology 100:143149. https://doi.org/10.1094/PHYTO-100-2-0143 